\title{
Identification of Y-Nauplii (Facetotecta) in Andaman Sea, India
}

\author{
V. Swathi, P. M. Mohan \\ Department of Ocean Studies and Marine Biology, Pondicherry University Off Campus, Port Blair, India \\ Email:pmmtu@yahoo.com,pmmnpu@rediffmail.com
}

How to cite this paper: Swathi, V. and Mohan, P.M. (2019) Identification of Y-Nauplii (Facetotecta) in Andaman Sea, India. Open Journal of Marine Science, 9, 137-147. https://doi.org/10.4236/ojms.2019.93011

Received: May 23, 2019

Accepted: July 19, 2019

Published: July 22, 2019

Copyright $\odot 2019$ by author(s) and Scientific Research Publishing Inc. This work is licensed under the Creative Commons Attribution International License (CC BY 4.0).

http://creativecommons.org/licenses/by/4.0/

\begin{abstract}
The Facetotecta is among the lesser known groups in the world ocean. The present study recorded two types of Facetotecta in the Andaman Sea, off Andaman Islands. These two types of Facetotecta were observed during the period of August 2015, July 2016 and October 2017 and identified as Type I Hansenocaris corvinae and Type IX Hansenocaris leucadea. However, the cursory analysis suggested that the Type IX is a new type of Facetotecta and named it as Type XII Hansenocaris portblairenae sp. (nov). This finding suggests that this Facetotecta observation is the first report in the Andaman Sea, as well as in the Indian Ocean Region.
\end{abstract}

\section{Keywords}

Y-Nauplii, Facetotecta, Andaman Sea, Andaman Islands, Indian Ocean

\section{Introduction}

The crustacean Facetotecta which has never been known for its adult, but identified as larvae called Y-larvae, has long been considered as a great mystery of zoological studies. Generally, it has been found from the poles to the tropics, that coral reef areas show very high diversity in marine planktons. The closest relatives of this larva are barnacles and Ascothoracida, which have also exhibited a similar larval form and parasitic nature. Due to its close similarity with Ascothoracida and Cirripedia, this Y-larvae/Y-nauplii has been named as facetotecta (subclass) by Grygier [1] [2] [3]. Ito [4] [5] [6] [7] and Kolbasov and Hoeg [8] proposed a genus based on the cypris morphology. Later, different collections from the world's oceans of this larvae necessitated classification of the scheme based on the plate nomenclature of the cephalic shield [9] [10]. The number and design in these shields have an important value for diagnosis of this larvae form. 
Most importantly, morphological features such as general shape, the dorso-caudal organ position, margins of the hind body and appendage armament are considered for its classification. At present, the classification has 13 different types of larvae indicated by Roman numerals (I to XI) and the VIII type subdivided into three subtypes. Ponomarenko [11] reviewed the morphological and research history of the infraclass Facetotecta [1]. It was found that this class described only larval stages and the adult is yet to be identified till date.

Ito [5] [6] reported three types of Y-Nauplii (Crustacea: Maxillopoda) from the North Pacific waters, Tanabe Bay, off the Seto Marine Biological Laboratory, which resemble Hansen's type I, IV and VII. This location was strongly influenced by the warm Kuroshio currents. However, Mileikocskii's [12] record showed that the coastal waters of northern Japan influenced the cold Oyashio currents. Belmonte [13] reported four new species of Y-Nauplii (Crustacea, Thecostraca, Facetotecta) from the coastal waters of the Salento Peninsula (southeastern Italy, Mediterranean Sea). This report is new to Europe and the type of these Nauplii belongs to I, IV, VII and IX. Ponomarenko and Korn [14] reported nauplii V of Facetotecta in Peter the Great Bay (Sea of Japan) and inferred that these larvae are transported from the coastal waters off Japan during summer to the study site.

Prior to this report, no existing literature reported that this species was identified in any of the Indian Seas and the Andaman Sea. A continuous monitoring of the planktons with reference to carbon accumulation on oligotrophic waters resulted in the identification of this species that also in a particular period, made this finding an interesting one.

\section{Materials and Methods}

Eight locations, which have coverage of a $50 \mathrm{~km}$ stretch of the nearshore environment of the Andaman Sea and represent the South Andaman geographical locations were sampled on a monthly basis (Chidiyatappu, Kodiyaghat South, Kodiyaghat North, Burmanallah, Carbyns Cove, Chatham and North Bay) from 2014 to 2017 (Figure 1). The physical parameters (Temperature, Salinity, pH, Turbidity and Depth) were measured in situ using Quanta-Hydrolab from Surface, $5 \mathrm{~m}, 10 \mathrm{~m}$ and $15 \mathrm{~m}$ depths. The water samples were collected using the Niskin water sampler in the same depth where physical parameters were observed. The collected water samples were preserved in $5 \mathrm{~L}$ high density polypropylene, acid cleaned water bags. These waters were analyzed onshore for Nitrite, Nitrate, Inorganic Phosphate and Reactive Silica using the standard procedure [15].

The plankton samples were collected using the standard phytoplankton net (mesh size of $30 \mu \mathrm{M}$ ) for a horizontal tow of about 10 minutes. The plankton sample was collected as a soup and latter its wet volume was estimated and the Facetotecta was separated based on the keys provided by Ito [5] [6], Mileikocskii [12], Ponomarenko [11] and Belmonte [13]. 


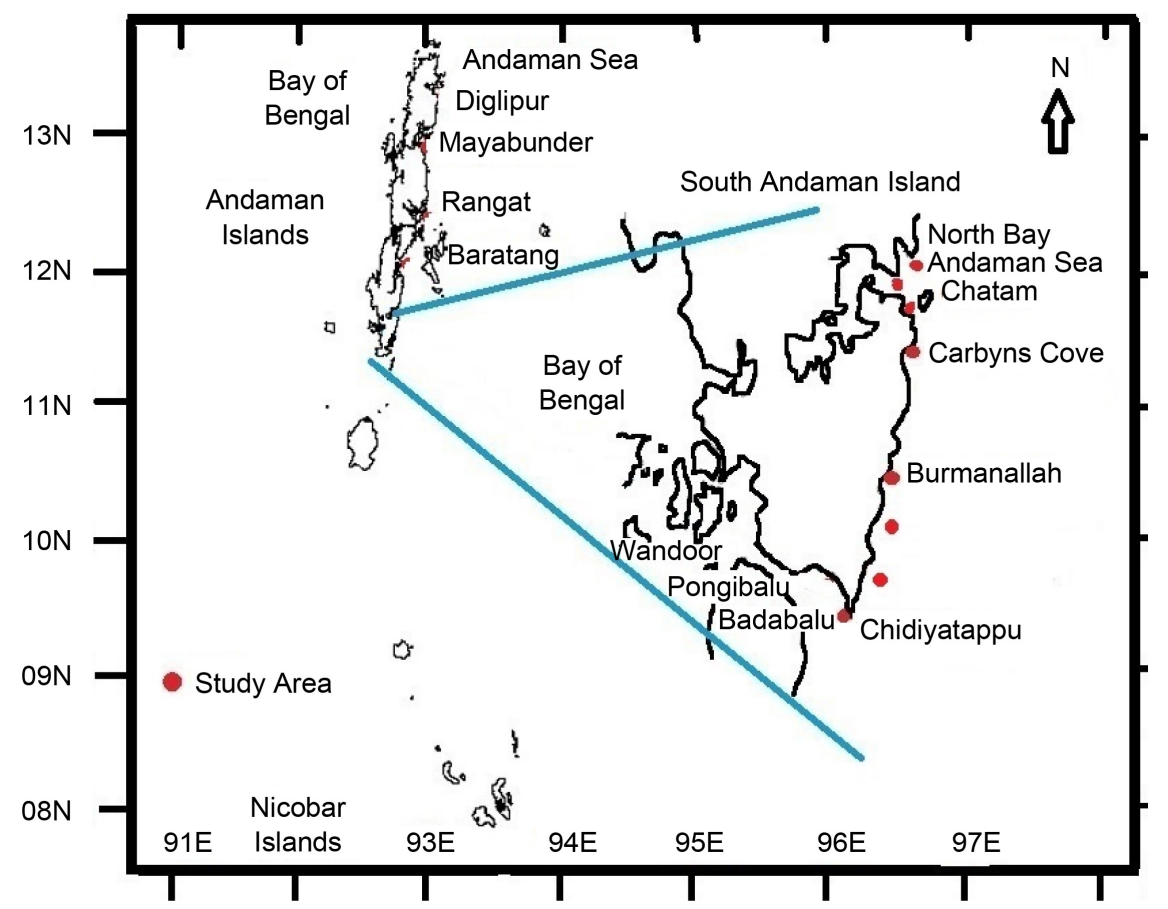

Figure 1. Study area.

\section{Results}

The forty eight (2014-2017) studied plankton samples suggested that during the months of August 2015, July 2016 and October 2017, some unknown specimens were observed, which were identified in the range of 1 to 5 numbers, i.e., August 2015-1 No., July 2016-5 Nos., and October 2017-1 No. These specimens were first identified as rotifer and then moved to small crustaceans. In the course of time, the identification search led to the rare larval form Y-Nauplii.

The taxonomy of the identified Y-nauplii is as follows.

\subsection{Hansenocaris corvinae}

\subsubsection{Morphology}

Embedded on it is a cephalic shield with cuticular ridges, cresentric and polygonal plates. It has a dorsocaudal organ protruding in lateral view. The spine like the terminal horn is shorter than two furcal spines in dorsal view. The margins of the hind body exhibited with spines, whose size increased towards the caudal extremity.

\subsubsection{Materials Examined}

One-Type I Y-nauplii from North Bay, August 2015. Five numbers from July 2016. The second samples were also collected from the same location. These specimen descriptions were also similar to the earlier one and were considered as similar specimens of August 2015.

\subsubsection{Holotype}

The specimen collected for the month of August 2015 was kept as a Holotype 
(One Number) for the Type I Y-nauplius of the Andaman Sea and Deposited at the Department of Ocean Studies and Marine Biology, Pondicherry University Off Campus, Port Blair, Andaman Islands (Reg. No. DOSMB 6053). This species length is $207 \mu \mathrm{m}$. Locality of collection: North Bay, Port Blair, Andaman and Nicobar Islands, Andaman Sea (Coordinates: Lat: $11^{\circ} 41^{\prime} 45.76 \mathrm{~N}$ : Long: $092^{\circ} 45^{\prime} 01.54 \mathrm{E}$ ). Collection Date: $21^{\text {st }}$ August 2015. Collector: Dr. P. M Mohan.

\subsubsection{Paratypes}

Five individuals, from the North Bay, were collected on $22^{\text {nd }}$ July 2016 at the Coordinates: Lat: $11^{\circ} 41^{\prime} 43.09 \mathrm{~N}$ : Long: $092^{\circ} 46^{\prime} 00.22 \mathrm{E}$ and deposited in the Department of Ocean Studies and Marine Biology, Pondicherry University Off Campus, Port Blair, Andaman Islands (Reg. No. DOSMB 6054-6058).

\subsubsection{Description}

The body length ranged from 207.1 to $288 \mu \mathrm{m}$ (6 Nos.) (mean-249.5 $\mu \mathrm{m}$ ). The dorsal view shows that the cephalic shield is separated from the hind body by a suture. The dorsal shape is cresentric, elongate and plates are embedded with polygonal shapes. The cuticular design of the plates is not in complete polygonal shape. The occipital field of the shield is not subdivided. The entire cuticle is marked with mesh, like the texture of the ridges. The length of the marginal spines increases towards the caudal region. The furcal spines are at the extremity of the hind body. The ventral part was also framed with carapace which is produced laterally and has marginal spines. These marginal spines belong to the dorsal plate of the hind body. There is a terminal spine, which is produced from the lower extremity of the ventral region and two more furcal spines which are parallel to each other and also longest in length. These furcal spines are longer than all other spines of the body (Figure 2 and Figure 3).

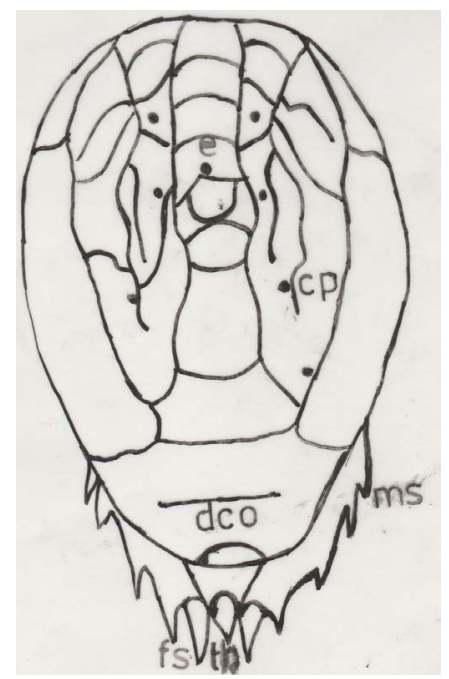

Figure 2. Type I-Hansenocaris corvinae species dorsal view. e-Eye; cp-Cuticle Pores; dco-Dorso Caudal Organs; ms-Marginal Spines; th-Terminal Horn; fs-Furcal Spines. 


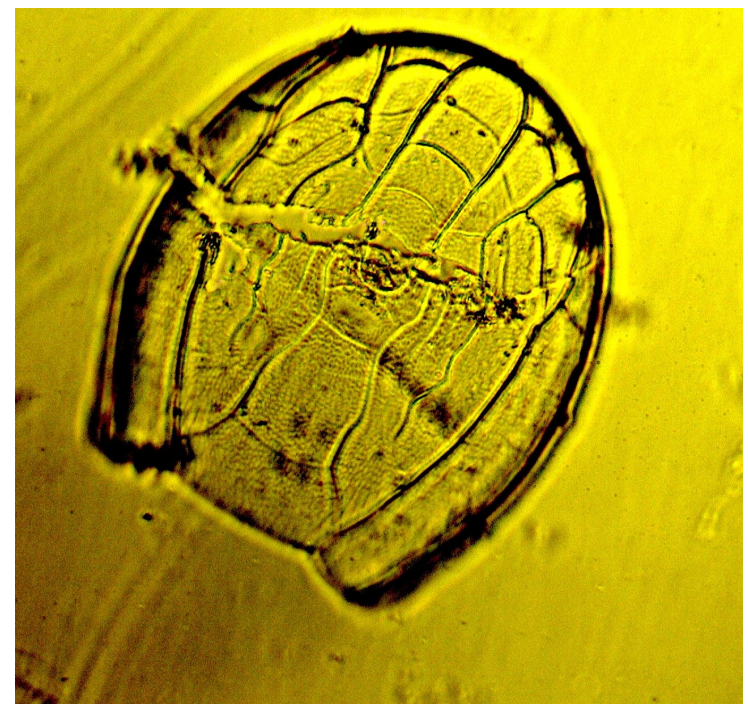

Figure 3. Microphotograph of type I-Hansenocaris corvinae species dorsal view (partially damaged during the photograph).

Its antennule is uniramous and well articulated. The distal article bears five setae (Figures 4-6). The second antenna is furnished with spiny medially oriented endites. Both the coxa and basis bear a spine. The coxa and basis of the mandible have spiny endites and the labrum is trilobiate. Numerous transverse cuticular ridges are present on the hind body.

\section{Taxonomy:}

Phylum: Arthropoda.

Subphylum: Crustacea.

Class: Maxillopoda.

Infraclass: Facetotecta (Grygier, 1985).

Family: Hansenocarididae (Ito, 1985).

Genus: Hansenocaris (Ito, 1985).

Species: corvinae (Belmonte, 2005).

Type Location: Crotta Delle Corvine, Santa Caterina in the Mediterranean Sea.

\subsection{Hansenocaris portblairenae Sp. (Nov)}

\subsubsection{Morphology}

It has a cephalic shield with cuticular ridges, elongate, cresentric and embedded with polygonal plates. The protruding dorsocaudal organs are visible from the lateral side. The terminal horn spine is more prominent than the two latero-ventral ones (furcal spines) in dorsal view. The margins of the hind body have spines whose size increases towards the caudal extremity.

\subsubsection{Material Examined}

One Y-nauplius from the North Bay was examined. This specimen was availed from the sample collected during the month of October 2017. The description of 


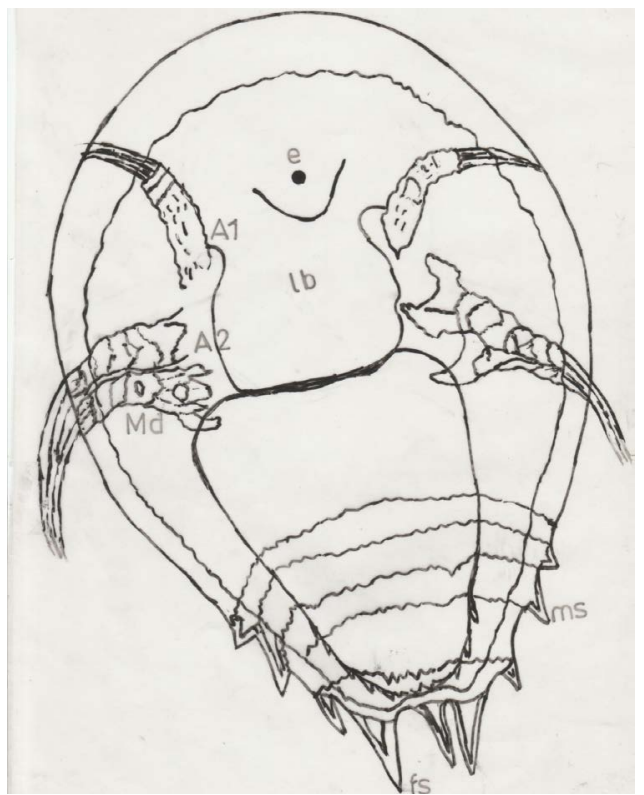

Figure 4. Type I-Hansenocaris corvinae species ventral view. e-Eye; lb-Labrum; A1-Antennula; A2-Antenna; Md-Mandible; ms-Marginal Spines; fs-Furcal Spines.

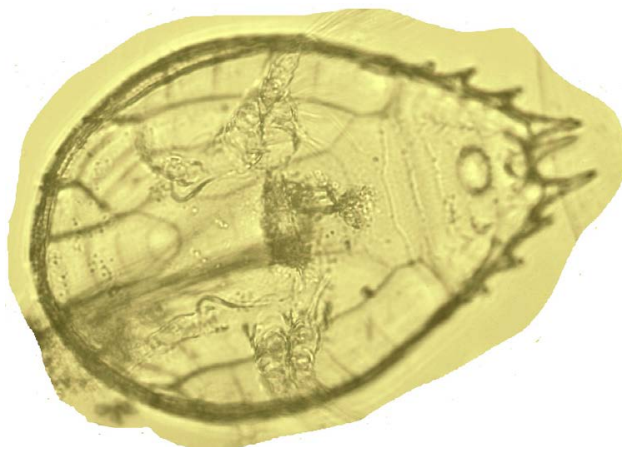

Figure 5. Microphotograph of Type I-Hansenocaris corvinae species ventral view.

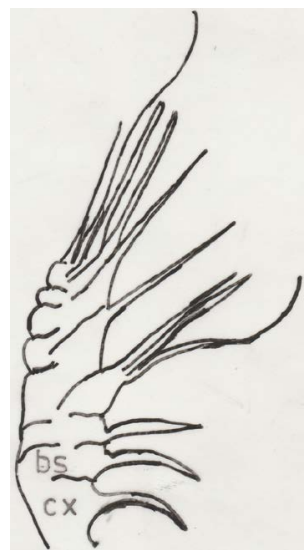

Figure 6. Type I-Hansenocaris corvinae species Antenna. bs-Basis; cx-Coxa. 
this species is unique compared to the already described species, this species description has been considered separately.

\subsubsection{Holotype}

Since, only one specimen was collected, this specimen was kept as a Holotype specimen and preserved in the Department of Ocean Studies and Marine Biology, Pondicherry University Off Campus, Port Blair, Andaman Islands, India (Reg. No. DOSMB 6059). This species has length of $294.65 \mu \mathrm{m}$. Locality of collection: North Bay, Port Blair, Andaman and Nicobar Islands, Andaman Sea (Coordinates: Lat: $11^{\circ} 41^{\prime} 42.44 \mathrm{~N}$ : Long: $092^{\circ} 45^{\prime} 01.62 \mathrm{E}$ ). Collection Date: $17^{\text {th }}$ October 2017. Collector: Dr. P. M. Mohan.

\subsubsection{Description}

The body length is $294.65 \mu \mathrm{m}$. The dorsal view shows the cephalic shield, which is separated from the hind body by a suture. These shield plates are cresentric, elongate polygonal, and are more complete in nature providing a better complete structure. The occipital field of the shield is subdivided. All the cuticle is decorated with a mesh like texture of the ridges. The cuticle of the hind body has a dorsocaudal organ from the posterior margin. The terminal spine is inserted at the end of the hind body. It is larger than each of the furcal spines from the dorsal view. The margins of the hind body are armed with spines and furcal spines are present. Furcal spines are at the extremity of the hind body. The length of the marginal spine increases towards the caudal direction. The ventral view, a medial region of the hind body is well distinguished with transverse cuticular ridges armed with spines. The antennule is uniramous and well articulated. The distal article bears four setae. The second antenna is furnished with medially directed spiny endites (Figure 7). Both the coxa and basis bear a spiny endite. The mandible is also furnished with spiny endites (Figure 8).

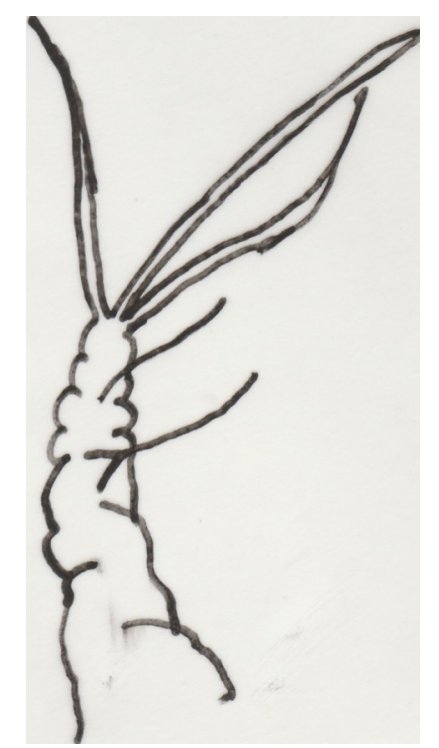

Figure 7. Type I-Hansenocaris corvinae species Antennula. 


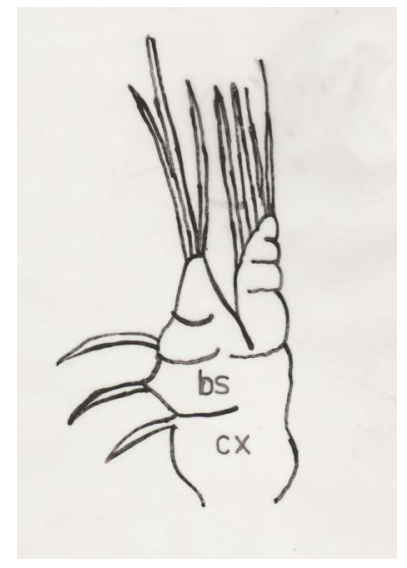

Figure 8. Type I-Hansenocaris corvinae species Mandible. bs-Basis; cx-Coxa.

\section{Taxonomy:}

Phylum: Arthropoda.

Subphylum: Crustacea.

Class: Maxillopoda.

Infraclass: Facetotecta (Grygier, 1985).

Family: Hansenocarididae (Ito, 1985).

Genus: Hansenocaris (Ito, 1985).

Species: portblairenae sp. (nov).

Type Location: North Bay, Port Blair, Andaman Islands, India.

\subsubsection{Etymology}

Y-nauplii was considered a new type because the availability of the terminal horn spine is more prominent than the two latero-ventral ones (furcal spines) in dorsal view. Further, the nearest Type Hansenocaris leucadea showed almost similar characters to Y-nauplii. However, the designated Y-nauplii Hansenocaris portblairenae sp. (nov)., differed mainly in terms of the embedded polygonal plate design, which showed almost a complete structure. Therefore, it has been considered as a new Type of Y-nauplii and named as a Type XII-Hansenocaris portblairenae sp. (nov). Port Blair is the nearest town to this sample location, hence a name was added and designated as a new species.

\section{Discussion}

The focused search of the identified Y-nauplii resulted in the identification of two tropical types of Facetotecta. They are Hansenocaris corvinae and Hansenocaris leucadea. However, the cursory analysis revealed that instead of Hansenocaris leucadea, the identified Y-nauplii description may lead to a new Type of Y-nauplii.

\subsection{Hansenocaris corvinae}

This Type, Y-nauplii byname is derived from the Corvine Grotto, a submerged 
cave on the Ionian coast of the Salento peninsula, where this species was found for the first time [13]. Further, the description of Ito [7] and Belmonte [13] of this species is similar to the present described species with a slight variation of the mean length, i.e. the mean length in the present study is $249.5 \mu \mathrm{m}$ whereas the earlier described specimen length is $288.9 \mu \mathrm{m}$. The variation of this size difference may be as a result of the different stages of instar or environmental parameters which existed in this location. The specimens were found from the same locations in two years. However, the collection period was somewhat different from this location, i.e. one collection in August and another one was in July. This also matches with the collection status of earlier reports, i.e., Belmonte [13] reported the samples of Y-nauplii collected by him in different months of the different years. Further, it was also recorded that this Y-nauplii of Type I, Hansenocaris corvinae has been identified and reported for the first time in the Andaman Sea, even in the Indian Ocean regions.

\subsection{Hansenocaris portblairenae Sp. (Nov)}

This Y-nauplius was found only in the month of October 2017, was not observed in other periods of study and was only from the North Bay. The difference in the cuticular plate design and complete absence of the pore associated sensilla made this species to be assigned as a separate entity. Other than that, all the remaining characters showed similarity with the species Type IX Hansenocaris leucadea Y-nauplii of the Mediterranean Sea as described by Belmonte [13]. According to these characters, it was considered a new type of Y-nauplii and named as a Type XII-Hansenocaris portblairenae sp. (nov) (Figure 9 and Figure 10).

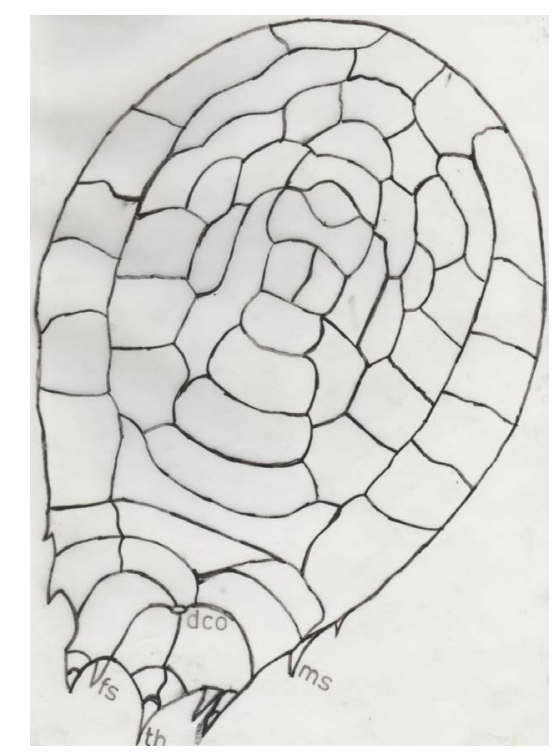

Figure 9. Type I - Type XII-Hansenocaris portblairenae sp. (nov). Dorsal View. dco-Dorso Caudal Organs; ms-Marginal Spines; th-Terminal Horn; fs-Furcal Spines. 


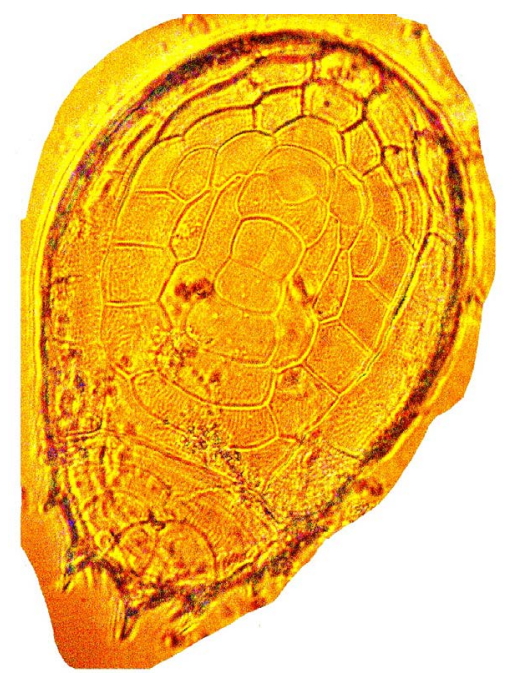

Figure 10. Microphotograph of Type XII-Hansenocaris portblairenae sp. (nov). Dorsal View.

\section{Conclusion}

The Andaman Islands, a part of the Andaman Sea, contained two species of Y-nauplii. One of the two species was identified as Type I-Hansenocaris corvinae. However, the second species was identified as a new species due to its variation in polygonal plates and the absence of pores related to sensilla and designated as Type XII-Hansenocaris portblairenae sp. (nov). Further, it has also been suggested that this is the first record in the Andaman Sea as well as the Indian Ocean waters. A detailed, continued monitoring of this water is essential to understand its further distribution and availability.

\section{Acknowledgements}

The authors thank the Authorities of the Pondicherry University for the facilities provided to conduct this research. Further, the authors thank the Indian Insistue of Tropical Meteorology (IITM), Ministry of Earth Sciences, Pune for providing the fund for estimation of carbon in the oligotrophic waters.

\section{Conflicts of Interest}

The authors declare no conflicts of interest regarding the publication of this paper.

\section{References}

[1] Grygier, M.J. (1985) Comparative Morphology and Ontogeny of the Ascothoracida, a Step toward a Phylogeny of the Maxillopoda. Dissertation Abstracts International, Section B, 45, 2466B-2467B.

[2] Grygier, M.J. (1987) New Records, External and internal Anatomy, and Systematic Position of Hansen's Y-Larvae (Crustacea: Maxillopoda: Facetotecta). Sarsia, 72, 261-278. https://doi.org/10.1080/00364827.1987.10419723

[3] Grygier M.J. (1996) Sous-classe des Facetotecta (Facetotecta Grygier, 1985). In: 
Forest, J., Ed., Traite’ de Zoologie, Crustace’s, Tome VII, Masson, Paris, 425-432.

[4] Ito, T. (1985) Contributions to the Knowledge of Cypris Y (Crustacea: Maxillopoda) with Reference to a New Genus and Three New Species from Japan. Special Publication of the Mukaishima Marine Biological Station, 30, 113-122.

[5] Ito, T. (1986) Three Types of "Nauplius Y" (Maxillopoda: Facetotecta) from the North Pacific. Publications of the Seto Marine Biological Laboratory, 31, 63-73. https://doi.org/10.5134/176117

[6] Ito, T. (1986) A New Species of "Cypris Y" (Crustacea, Maxillopoda) from the North Pacific. Publications of the Seto Marine Biological Laboratory, 31, 333-339. https://doi.org/10.5134/176123

[7] Ito, T. (1989) A New Species of Hansenocaris (Crustacea: Facetotecta) from Tanabe Bay, Japan. Publications of the Seto Marine Biological Laboratory, 34, 55-72. https://doi.org/10.5134/176158

[8] Kolbasov, A.G. and Høeg, J.T. (2003) Facetotectan Larvae from the White Sea with the Description of a New Species (Crustacea: Thecostraca). Sarsia, 88, 1-15. https://doi.org/10.1080/00364820308471

[9] Ito. T. (1987) Proposal of new terminology for the morphology ofnauplius y (Crustacea: Maxillopoda: Facetotecta), with provisionaldesignation of four naupliar types from Japan. Zoological Science, 4, 913-918.

[10] Ito, T. (1990) Naupliar Development of Hansenocarisfurcifera Ito (Crustacea: Maxillopoda: Facetotecta), from Tanabe Bay, Japan. Publications of the Seto Marine Biological Laboratory, 34, 201-224. https://doi.org/10.5134/176166

[11] Ponomarenko, E.A. (2006) Facetotecta-Unsolved Riddle of Marine Biology. Russian Journal of Marine Biology, 32, S1-S10. https://doi.org/10.1134/S1063074006070017

[12] Mileikovskii, C.A. (1970) The Distribution of Pelagic Larvae of Bottom Invertebrates in the Kuri1-Kamchatka Region. Tr. IO AN SSSR, 86, 117-133. (In Russian)

[13] Belmonte, G. (2005) Y-Nauplii (Crustacea, Thecostraca, Facetotecta) from Coastal Waters of the Salento Peninsula (South Eastern Italy, Mediterranean Sea) with Descriptions of Four New Species. Marine Biology Research, 1, 254-266. https://doi.org/10.1080/17451000500202518

[14] Ponomarenko, E.A. and Korn, O.M. (2006) First Record of a Facetotectan Crustacean in Plankton of Peter the Great Bay, Sea of Japan. Russian Journal of Marine Biology, 32, 299-301. https://doi.org/10.1134/\$1063074006050063

[15] Grasshoff, K., Ehrhardt, M. and Kremling, K. (1999) Methods of Seawater Analysis. Verlag Chemie, Weinheim, 419 p. https://doi.org/10.1002/9783527613984 